\title{
Correction to: Ultrasound in forearm fractures: a pragmatic study assessing the utility of Point of Care Ultrasound (PoCUS) in identifying and managing distal radius fractures
}

\section{Darryl Wood ${ }^{1}$ (D) Maruteshwar Reddy ${ }^{1} \cdot$ Ignatius Postma $^{1} \cdot$ Paul Bromley $^{1} \cdot$ John Hambridge $^{1}$.} Chandu Wickramarachchi ${ }^{1} \cdot$ Ahamed Syed Hameed $^{1}$

Published online: 21 July 2021

(c) American Society of Emergency Radiology 2021

Correction to: Emergency Radiology (2021)

https://doi.org/10.1007/s10140-021-01957-8

The original article contains a spelling error in Author name. Instead of "Wickremarachchi" it should be "Wickramarachchi".

The original article has been corrected.

Publisher's note Springer Nature remains neutral with regard to jurisdictional claims in published maps and institutional affiliations.

The original article can be found online at https://doi.org/10.1007/ s10140-021-01957-8.

Darryl Wood

darrylrwood@yahoo.co.uk

1 Barking, Havering and Redbridge University Hospitals

Trust, Queens Hospital, Rom Valley Way, Romford,

London RM7 0AG, UK 